\author{
Cristina Sylla \\ CIEC-engageLab \\ University of Minho \\ Braga, Portugal \\ sylla@engagelab.org
}

Vítor Carvalho

School of Technology

Polytechnic Institute of Cávado

and Ave - Algoritmi

University of Minho

Barcelos-Guimarães, Portugal

vcarvalho@ipca.pt

\title{
Record, Play, Go...
}

\author{
Eva Oliveira \\ Digarc - School of Technology \\ Polytechnic Institute of Cávado \\ and Ave \\ Barcelos, Portugal \\ eoliveira@ipca.pt
}

\author{
Joaquim Dantas \\ School of Technology \\ Polytechnic Institute of Cávado \\ and Ave, \\ Barcelos, Portugal \\ a6868@alunos.ipca.pt
}

\author{
Pedro Branco \\ Algoritmi - engageLab \\ University of Minho \\ Guimarães, Portugal \\ pbranco@dsi.uminho.pt
}

\begin{abstract}
This workshop aims at stimulating children's oral language skills by involving them on playing and creating different language games or activities using the t-stories interface. The interface allows recording and playing audio on the tstories' modules, as well as recording and playing based on identification with NFC tags that can be used as sticker on objects, paper, or other materials and placed in different locations. After the presentation of t-stories by the workshop facilitators, children will have the opportunity to explore the interface on their own, then they will be asked to participate in different language games, whereby they actively create their own content. Afterwards children will be challenged to imagine and create activities for their peers.
\end{abstract}

\section{Author Keywords}

Tangible Interfaces; Story Listening System; Children; Exploration; Emergent Literacy; Phonological Awareness.

\section{ACM Classification Keywords}

H.5.2 Information Interfaces and Presentation (e.g.,

$\mathrm{HCI}$ ): User Interfaces, user-centered design. K.3.0

[Computers and Education]: General.

\section{INTRODUCTION}

Children's language and literacy skills form the foundation

\footnotetext{
Permission to make digital or hard copies of part or all of this work for personal or classroom use is granted without fee provided that copies are not made or distributed for profit or commercial advantage and that copies bear this notice and the full citation on the first page. Copyrights for thirdparty components of this work must be honored. For all other uses, contact the Owner/Author.

Copyright is held by the owner/author(s).

ACE '15, November 16-19, 2015, Iskandar, Malaysia

ACM 978-1-4503-3852-3/15/11.

http://dx.doi.org/10.1145/2832932.2832963
}

of a good academic achievement $[1,5,9]$; therefore it is of major importance that children engage in activities that promote the development of these skills. Story listening systems [3] are non-screen-and-keyboard-based technologies that naturally lead the users to concentrate on the audio component of the language, having the potential to fostering early literacy skills while promoting a playful acquisition of language related skills such as phonological, lexical and metalinguistic awareness. Phonological awareness referrers to the ability of identifying and manipulating units of oral language, such as words, syllables, onsets and rhymes; lexical awareness is the knowledge of vocabulary; and metalinguistic awareness is the ability to reflect about the language itself.

\section{THE T-STORIES INTERFACE}

$\mathrm{t}$-stories was developed with the aim at promoting collaborative playful exploration of the language. The interface builds on previous work by $[7,8]$, however it extends the capabilities of the previous system. t-stories is composed by 10 client modules and a server module; each module has a slot on the upper surface for placing paper cards and a surface for drawing on the backside. The client modules have magnets on each side that connect to each other and to the server module (fig.1 top). To record on a client module, users place the server module over it and record while pressing a button (fig. 1 middle).

To play the recorded audio users can connect the client modules to the server module, which plays the audio from left to right (allowing users to change the sequences), or alternatively, users can hold the server module over each of the client modules (fig.1. bottom).

Additionally, t-stories also allows recording and playing audio based on the identification of NFC tags that can be 
used as stickers on objects, paper, or other materials and placed on different locations.
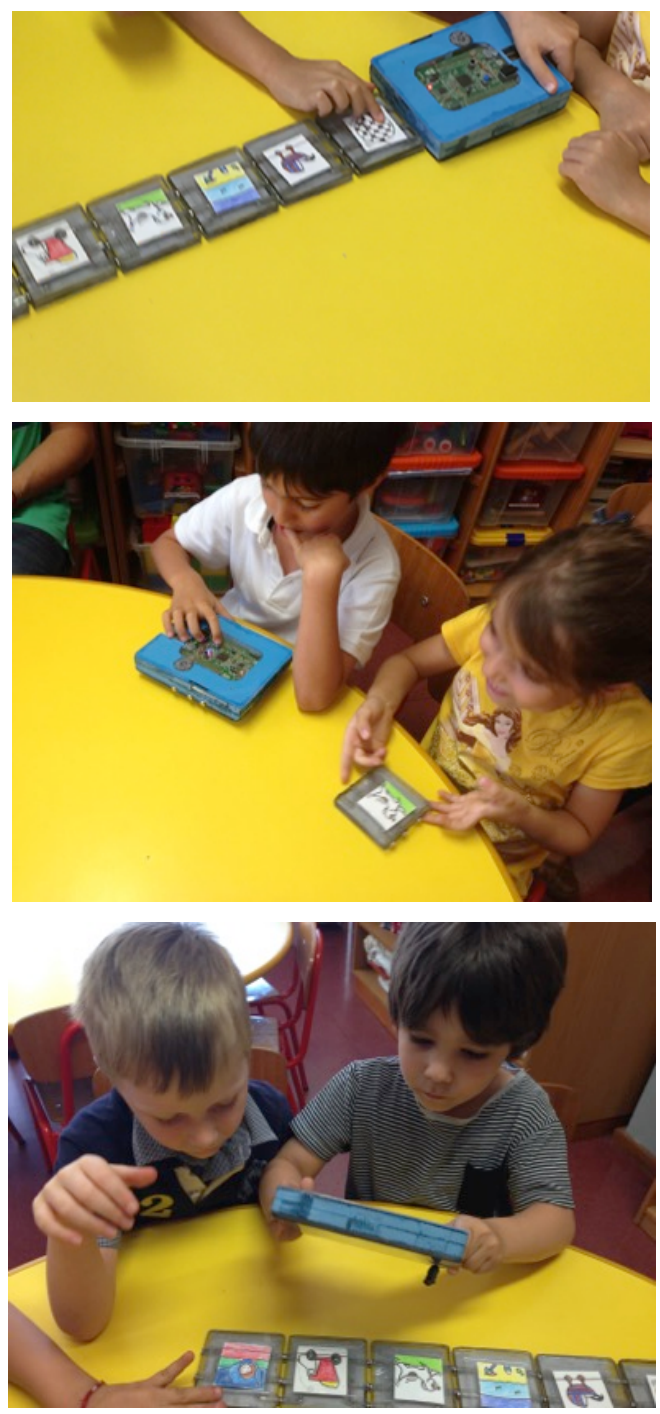

Figure 1. Children playing the sequence by connecting the clients to the server (top), recording a client (middle) and preparing to hear the sequence (bottom).

\section{BACKGROUND}

The $\mathrm{t}$-stories interface aims at engaging children in collaborative playful exploration of the oral language, by allowing them to create a wide diversity of language related activities. As children are free to create and play their own audio content, the interface has the potential to promote reflection over children's verbal compositions, while promoting creativity and collaboration. This potential is strengthened by the possibility of physically handling the speech units (recorded in the different modules) rearranging them to hear different audio sequences, as well as to create "spoken narratives" that users can stick to different objects or materials (e.g. children can complement their drawings with a story/description/message that they record using identification based on NFC tags, and stick the tags on their drawings). t-stories combines characteristics from other story telling systems such as TellTale [2], StoryMat [4], t-words [7,8], or Jabberstamp [6], but can also be differentiated from them due to its robustness and ease of use, while at the same time bringing together characteristics that are present in the different referred interfaces. Thus, t-stories allows recording and playing in different client modules that can then be snapped together (like TellTalle and t-words), as well as drawing (TellTalle, t-words, Jabberstamp), however, besides supporting recording and playing audio in each of the t-stories modules, the interface allows recording (and playing) audio using identification based on NFC tags that can be used as stickers on objects, paper, or other materials. Also, besides playing the recorded audio following the position of the snapped modules (from left to right (as t-words or Telltale), t-stories allows randomly hearing each client module separately (in this case the client module does not need to be attached to other client modules), by placing the server module over it. This also allows users to randomly hear each client module, and change the playing sequence by moving from one client module to the next (which can be even scattered over the place).

\section{WORKSHOP AIMS AND SCOPES}

The motivation behind this workshop is to present children with technological innovative ways of language exploration as well as stimulating their imagination, collaboration, critical reflection and exchange of ideas. Children will also be challenged to imagine and propose activities to be carried by their peers. Further, the researchers expect to get new insights on how children see the interface, the kind of activities they create, as well as whether t-stories is capable of motivating children to engage in playful activities.

\section{General Overview of the Workshop}

The workshop addresses children between six and seven years of age, in a total of 12 children. The duration of the workshop is approximately 4 hours. After the first introductory phase, where children and facilitators will get acquainted with each other, the workshop facilitators will present the interface to the children and demonstrate how to use it. Children will be shown how to record a t-stories module, and two possible ways to play the recorded audio:

- by attaching the client modules to the server module whereby the audio will be played from left to right following the sequence of the client modules (users can randomly change the order of the modules);

- or holding the server module over particular client modules.

The facilitators will also show children the possibility of drawing on the upper surface of the client modules as well as on paper cards that can be stuck to the other side of the modules. After that the children will explore the t-stories interface on their own, experimenting how to record on the 
client modules and how to play the recorded audio creating different audio sequences.

Children will then be divided in small groups; each group will get a t-stories interface (one master and 10 servers) as well as drawing materials. Now that children master the use of the interface the workshop facilitators will propose various language games to the groups, in which children will be challenged to create different language compositions and explore different combinations of speech units.

Following the first set of activities with the t-stories modules, the facilitators will present the NFC tags to the children and exemplify how to use them, showing the possibility of recording audio with the tags and stick them to objects, paper or other materials. Each group will be given a set of NFC tags and asked to create a challenge using the tags that they will propose to the other groups. After creating the activity, each group will present it to the other participants and the groups will then carry the proposed tasks. In the last part of the workshop the groups will be encouraged to change opinions about each other's work, and reflect all together about the different activities.

\section{WORKSHOP EXPECTATIONS}

As outcome of this workshop the organizers expect that the children explore the full potential of the interface and that the kind of proposed activities promote teamwork and collaboration between the children, triggering their imagination, change of ideas and reflection over their compositions. They also expect to get new insights on how children view the interface, the kind of activities that they create using it, and to which extent the interface is capable of engaging children in activities that they enjoy.

\section{ACKNOWLEDGMENTS}

We thank the kindergarten Bogalha in Braga-Portugal, the children and their teacher for their wonderful collaboration in this study. This work was partially supported by FCT Portuguese Foundation for the Science and the Technologywithin the Projects: UID/CED/00317/2013 and

UID/CEC/00319/2013.

\section{REFERENCES}

1. Adams, M.J., Foorman, B.R., Lundberg, I., Beeler, T. 1998. Phonemic awareness in young children: A classroom curriculum. Baltimore, MD: Brookes Publishing Co.
2. Ananny, M. 2001. Telling Tales: A new toy for encouraging written literacy through oral storytelling. In Proceedings of the Biennale Conference Society for Research in Child Development. Minneapolis.

3. Cassel, J. 2004. Towards a model of technology and literacy development: Story listening systems. Journal of Applied Developmental Psychology, 25, 75-105.

4. Cassell, J., Ryokai, K. 2001. Making Space for Voice: Technologies to Support Children's Fantasy and Storytelling. Journal Personal Technologies, 5(3), 203224.

5. Perfetti, C.H., Landi, N., Oakhill, J. 2009. "The Acquisition of Reading Comprehension Skill”, The Science of Reading (3rd ed.), M.J. Snowling, C. Hume, eds., MA-USA, UK, and Australia: Blackwell Publishing, 227-247.

6. Raffle, H., Vaucelle, C., Wang, R. and Ishii, H. 2007. Jabberstamp: embedding sound and voice in traditional drawings. In Proceedings of the International SIGGRAPH Conference on Computer Graphics and Interactive Techniques, (SIGGRAPH '07) 137-144. New York, NY: ACMPress.

7. Sylla, C., Gonçalves, S., Branco, P., Coutinho, C. 2012. t-words: Playing with Sounds and Creating Narratives. In A. Nijholt, T. Romão \& D. Reidsma (Eds.), Proceedings of the 9th International Conference on Advances in Computer Entertainment Technology, ACE'12, Kathmandu, Nepal, November 3-5, pp. 565568. Lecture Notes In Computer Science, Springer. DOI: 10.1007/978-3-642-34292-9.

8. Sylla, C., Gonçalves, S., Branco, P., Coutinho, C. 2013. Peter Piper Picked a Peck of Pickled Peppers - an Interface for Playful Language Exploration. In Proceedings of the SIGCHI Conference on Human Factors in Computing Systems (CHI '13), 3127-3130. doi:10.1145/2468356.2479627.

9. Whitehurst, G.J., Lonigan, C.J. 1998. "Child Development and Emergent Literacy", Child Development, vol. 69, no. 3, pp. 848-72. Systems (CHI '02), 1-8. http://doi.acm.org/10.1145/503376.503378 